\title{
Orbitopatía tiroidea
}

\author{
Doctor \\ Enrique Ardila \\ Editor \\ Revista Colombiana de Endocrinología, Diabetes y Metabolismo
}

Apreciado Dr. Ardila:

$\mathrm{L}$ a enfermedad de Graves (EG) es una de las patologías más interesantes que competen al endocrinólogo. Siempre consideré que la orbitopatía (OG) era una rueda suelta en el manejo de la EG (además del más raro mixedema pretibial), y parecía que los oftalmólogos tampoco estaban muy familiarizados con ella. Algunos insistían en usar los epónimos de sus signos oculares, lo que nunca me pude aprender, y parece que ya se ha olvidado.

Los signos oculares aparecen aproximadamente en 1 de cada 4 pacientes, y cuando esto ocurre (además de encaminar al médico hacia el diagnóstico), generalmente son de naturaleza leve. Las OG moderadas y severas afortunadamente son menos frecuentes; el artículo de Gómez y colaboradores (1) nos actualiza en tan difícil tema.

La preferencia del endocrinólogo sobre el tratamiento de la EG ha variado a través del tiempo. La tiroidectomía fue la primera en desacreditarse porque, como se hacían subtotales, permitían la recurrencia del remanente tiroideo. Los antitiroideos, al principio muy de moda, empezaron a ser menos utilizados por el alto porcentaje de recurrencia. Algún autor recomendaba el uso concomitante de triyodotironina para disminuir los relapsos; sin embargo, el yodo radiactivo (I-131) empezó a posicionarse de primeras por su alta eficacia en la prevención de recurrencias, aunque había que manejar el hipotiroidismo de manera constante.

En cuanto a la OG y el manejo de la EG, se hablaba de usar métodos menos radicales (como el I-131 o la tiroidectomía) para intentar prevenirla. La revisión sistemática de Gómez y colaboradores (1) concluye de manera tajante que no se debe usar la radioyodoterapia en casos de OG moderada a severa, y en su lugar deben utilizarse tionamidas (a largo plazo después de la primera recurrencia) o debe realizarse una tiroidectomía total.

El grupo italiano de Bartalena es uno de los más activos en la investigación tanto de EG como de OG. De hecho, en 2018 Bar- talena escribe un capítulo sobre las complicaciones de la EG en el endotext.org: en él es claro su interés en la asociación entre el tabaquismo y la OG, y se muestra partidario del uso concomitante de esteroides orales si se usa el yodo radiactivo y de añadir selenio; además, señala que el tema de la terapia ablativa frente a la no ablativa continua siendo objeto de debate, y que los argumentos a favor o en contra tienen que ver con la parte autoinmune $(2,3)$. Cabe destacar que la revisión de Gómez aclararía el dilema prácticamente abandonando de la ablación con yodo radiactivo en los casos de OG moderada a severa. Según la literatura, parece que en Europa la OG tuviera una prevalencia en descenso, al menos en algunas variantes, y que en dicho continente la EG tuviera características de mayor levedad.

Considero que la OG moderada a severa debe ser manejada por un grupo multidisciplinario conformado por especialistas con experiencia en el tema. Ciertamente debe ser referida a centros mejor dotados para tomar decisiones, y se deben usar inmunosupresores o hacer tiroidectomías totales. El manejo médico con esteroides parece obtener mejores resultados en los casos inflamatorios, mas no en los casos crónicos con tejido cicatricial.

En una época la Asociación Colombiana de Endocrinología (ACE) solía hacer encuestas entre los endocrinólogos sobre temas como este. No sé cuánta participación tuvo, pero creo necesario conocer la experiencia de nuestros colegas en el manejo de la OG.

Atentamente,

Alfredo Jácome Roca Médico Internista, Endocrinólogo. Expresidente y Miembro Honorario de la Asociación Colombiana de Endocrinología, Diabetes y Metabolismo.

\section{Referencias}

1. Gomez C, Imitola A, Taboada LB et al. Orbitopatía tiroidea: protocolo de manejo basado en revisión de la evidencia. Rev Col Endocrinol Diab Metab. 2019;6(3):210-217.

2. Bartalena L. Graves' Disease: Complications. [acceso 20 de febrero de 2020]. En: Feingold KR, Anawalt B, Boyce A, et al., editores. Endotext [Internet]. South Dartmouth (MA): MDText.com, Inc.; 2000. Disponible en: https://www.ncbi.nlm.nih.gov/books/NBK285551/

3. Rosetti S, Tanda ML, Veronesi G, Masiello E, Premoli P, Gallo D, et al. Oral steroid prophylaxis for Graves' orbitopathy after radioactive iodine treatment for Graves' disease is not only effective, but also safe. J Endocrinol Invest. 2020 Mar;43(3):381-383. 